\title{
Perfection Of Methods Of Mathematical Analy- sis For Increasing The Completeness Of Subsoil Development
}

\author{
Mariya Fokina $^{1 *}$ \\ ${ }^{1}$ South Ural State University, 454080, 76 Lenina ave., Chelyabinsk, Russia
}

\begin{abstract}
The economy of Russia is based around the mineral-raw material complex to the highest degree. The mining industry is a prioritized and important area. Given the high competitiveness of businesses in this sector, increasing the efficiency of completed work and manufactured products will become a central issue. Improvement of planning and management in this sector should be based on multivariant study and the optimization of planning decisions, the appraisal of their immediate and long-term results, taking the dynamic of economic development into account. All of this requires the use of economic mathematic models and methodsApplying an economic-mathematic model to determine optimal ore mine production capacity, we receive a figure of $4,712,000$ tons. The production capacity of the Uchalinsky ore mine is 1560 thousand tons, and the Uzelginsky ore mine -3650 thousand. Conducting a corresponding analysis of the production of OAO "Uchalinsky Gok", an optimal production plan was received: the optimal production of copper - 77961,4 rubles; the optimal production of zinc -17975.66 rubles. The residual production volume of the two main ore mines of OAO "UGOK" is 160 million tons of ore.
\end{abstract}

\section{Introduction}

Russia is the richest country in terms of natural resources. Mining industry occupies an important place in the country's economy, providing 10\% of the GDP of the Russian Federation. But, according to actual data, the level of natural resources usage is on average $17 \%$ of the technologically possible one. It is also necessary to increase an investment in this industry, since they represent only $1 \%$ of the revenues that this industry provides. Thus, it becomes important to increase the pace of domestic mining industry development to the level of developed countries. The tasks set by the country's metallurgical industry require further improvement of the planning and management systems in the industry. In the conditions of high competitiveness of enterprises in this industry, the issue of improving the efficiency of the work and products becomes very important. The growth of industrial production has led to the accumulation of more than 100 billion tons of industrial waste on the country's territory and constant growth of their quantity continues nowadays. At the same time, about $35 \%$ of the total waste generated during the year is used and rendered harmless.

${ }^{*}$ Corresponding author: gva.pm@kuzstu.ru 
The need for recultivation of lands, disturbed by mining operations, and the lack of territories for the construction of landfills for waste disposal leads to the use of quarries for keeping there industrial waste of the mining industry. The location of industrial wastes of various industries in the quarry capacity allows expanding the exploration of the Earth's interior, as well as gaining additional profit from the implementation of such projects.

\section{Materials and methods}

The existing scientific and methodological base for the design and formation of mining structures does not take into account the purposeful usage of the worked out space for the disposal of industrial wastes, which hinders the increase of integrated development efficiency of subsurface resources.

It is necessary to fulfill the basic requirements for the rational use and protection of mineral resources, which are as follows:

1) observance of the procedure for granting subsurface resources for usage and prohibiting unauthorized usage of subsoil;

2) ensuring the completeness of geological study, rational integrated usage and conservation of mineral resources;

3) conducting advanced geological study of subsoil, providing a reliable estimate of mineral reserves or properties of the subsoil plot granted for usage for purposes not related to the extraction of minerals;

4) carrying out state expertise and state accounting of mineral resources, as well as subsoil plots used for purposes not related to the extraction of minerals;

5) ensuring the most complete extraction from the depths of reserves of basic and jointly occurring minerals and associated components;

6) true recording of recoverable and retained in the bowels of reserves of basic and jointly occurring minerals and associated components in the development of mineral deposits;

7) protection of mineral deposits from flooding, fires and other factors that reduce the quality of minerals and the industrial value of deposits or complicate their development;

8) prevention of subsoil contamination during subsoil usage, especially in the underground storage of oil, gas or other substances and materials, disposal of waste of I-V hazard classes, wastewater discharges, placement of associated waters and waters in rock formations used by users of subsoil for own production and technological needs;

9) observance of the established order of conservation and liquidation of enterprises for the extraction of minerals and underground structures not related to the extraction of minerals;

10) prevention of unauthorized development of mineral deposits and compliance with the established procedure for the use of these areas for other purposes;

11) prevention of the disposal of production and consumption wastes in the catchment areas of underground water bodies and in groundwater areas that are used for the purposes of drinking water supply or technological water supply to industrial facilities or agricultural facilities or which reservation is carried out as sources of drinking water supply.

Thus, the purpose of this research is to improve the efficiency of mining enterprises using an improved mathematical model for the improvement of a developed section of the Earth's interior.

To formulate the strategy for further development of JSC UGOK, it is necessary to solve the following tasks:

- to prove that UGOK is a self-sufficient enterprise and does not receive financing from the main Holding of the "Ural Mining and Metallurgical Company"

- to determine the optimal production plan for the given enterprise; 
- to form conclusions and proposals for further development of JSC "UGOK".

Before modeling and analyzing the activities of JSC UGOK, and before forming a strategy for further development, we will determine how high the financial stability of this enterprise is.

In order to prove that UGOK is a self-sufficient enterprise and does not receive financing from the main Holding, we need to consider the model of the optimal allocation of investments.

Let's write down the mathematical model of the task. We will find the optimal set of investment allocation:

$$
X^{*}=\left(x_{1}^{*}, x_{2}^{*}, \ldots, x_{k}^{*}, \ldots, x_{n}^{*}\right)
$$

satisfying the following conditions:

$$
\left\{\begin{array}{c}
x_{i} \geq 0 ; i=1, \ldots n \\
\sum_{i=1}^{n} x_{i}=B
\end{array}\right.
$$

Then we will divide the optimization process into $n$ steps and at each $k$ - th step we will optimize the investment of not all enterprises, but only enterprises with the $k$-th to the $n$-th. At the same time, it is natural to assume that funds are invested in other enterprises (from the first to $(k-1)-\mathrm{e}$ ), and therefore not all funds remain for investment of enterprises from $k$-th to $n$-th, but some smaller amount $C_{k} \leq B$. This value will be the state variable of the system.

The control variable at the $k$-th step is the amount $x_{k}$ of funds invested in the $k$-e enterprise. As a function of Bellman $F_{k}\left(C_{k}\right)$ at the $k$-th step, we can choose the maximum possible income that can be obtained from enterprises from $k$-th to $\mathrm{n}$-th, provided that their investment remains $C_{k}$ of funds. It is obvious that investing $x_{k}$ of the funds in $k$-th the enterprise will provide profit $g_{k}\left(x_{k}\right)$, and the system will have moved move to the state $(k+1)$ to the state $S_{k}+1$ and, consequently, the investment of enterprises from the $(k+1)$ - th to the next $n$ will remain $C_{k}+1=\left(C_{k}-x_{k}\right)$ of funds [3].

Thus, at the first step of conditional optimization $k=n$, the Bellman function represents profit only from the enterprise from the $n$. At the same time, the amount of money remaining to invest in it $C_{n}, 0 \leq C_{n} \leq B$. To get the maximum profit from this enterprise, you can invest in it all these funds, i.e., $F_{n}\left(C_{n}\right)=g_{n}\left(C_{n}\right)$ and $x_{n}=C_{n}$.

At each subsequent step to calculate the Bellman function, it is necessary to use the results of the previous step .

Let it be at the $k$-th step for investing enterprises from the $k$-th to n-th left money $C_{k}$ ( $\left.0 \leq C_{k} \leq B\right)$. Then, from the investment in $k$-e the enterprise $x_{k}$ of the funds will receive a profit $g_{k}\left(C_{k}\right)$, and the investment of the remaining enterprises will remain $C_{k}+1=\left(C_{k}-x_{k}\right)$ of the funds. The maximum possible income that can be received from enterprises will be:

$$
\mathrm{F}_{\mathrm{k}}\left(\mathrm{C}_{\mathrm{k}}\right)=\max _{\mathrm{x}_{\mathrm{k} \leq \mathrm{C}_{\mathrm{k}}}}\left\{\mathrm{g}_{\mathrm{k}}\left(\mathrm{x}_{\mathrm{k}}\right)+\mathrm{F}_{\mathrm{k}+1}\left(\mathrm{C}_{\mathrm{k}}-\mathrm{x}_{\mathrm{k}}\right)\right\} ; \mathrm{k}=1, \ldots \mathrm{n} .
$$


The value of the Bellman function $F_{1}\left(C_{1}\right)$ is the maximum possible income from all enterprises, and the value $x_{1}^{*}$ at which the maximum income is achieved is the optimal amount of funds invested in the first enterprise. Then, at the stage of unconditional optimization for all subsequent steps, the value $C_{k}=\left(C_{k-1}-x_{k-1}\right)$ of the optimal control at the $k$-th step is calculated to be the value $x_{k}$ that provides the maximum revenue with the corresponding state of the system $S_{k}$.

To solve the second problem, consider a multi-product model of production management. Considering that $C_{1}$ is the cost of production per unit of production per unit time, $q$ is the volume of output, $t_{s}$ is the time between recharges, and $n=T / t_{s}=R / q$ is the number of replenishment periods, the expression for the total cost of production in this case has the following form [4]:

$$
\mathrm{D}=\left(\frac{\mathrm{c}_{1} \mathrm{qt}_{\mathrm{s}}}{2}+\mathrm{C}_{\mathrm{s}}\right) \cdot \mathrm{n}=\frac{\mathrm{c}_{1} \mathrm{qT}}{2}+\frac{\mathrm{C}_{\mathrm{s}} \mathrm{R}}{\mathrm{q}}
$$

It is assumed that the demand for products is constant and within the time interval $\mathrm{T}, \mathrm{R}$ units will be sold. The optimum value for the volume of the replenishment product is determined from the condition that the next derivative $d D / d q=0$.

Solving this equation, we determine the value of the optimal replenishment of reserves $q$ :

$$
\mathrm{q}^{*}=\sqrt{\frac{2 \mathrm{C}_{\mathrm{S}} \mathrm{R}}{\mathrm{c}_{1} \mathrm{~T}}}
$$

In the presence of many products, the use of this formula becomes difficult, because for each product will determine its optimal value of the purchased product and it's time to resume delivery.

To overcome such difficulties, the idea arises to produce products of several types simultaneously so that by the beginning of the next stage of production the previous batch of products would become zero.

The costs of production during the period between replenishments will be:

$$
\overline{\mathrm{D}}=\sum_{\mathrm{i}=1}^{\mathrm{L}} \frac{\mathrm{c}_{\mathrm{i}} \mathrm{q}_{\mathrm{i}} \mathrm{t}_{\mathrm{s}}}{2}
$$

where $\mathrm{L}$ - number of product types in a group, $q_{i}$ - number of units of the $i$-th product, $t_{s}$ - time interval, $c_{i}$ - the cost of producing a unit of product $i$-type in a unit of time.

Since the demand $r_{i}$ for the $i$-th product is constant, the volume of ordered products should be equal to the quantity of output that will be consumed within a time $t_{s}$, i.e $q_{i}=r_{i} t_{s}$.

Based on the assumptions made, the total costs for storage and delivery organization for a group of products take the form: 


$$
D(q)=\left(\widetilde{D}+C_{s}\right) \cdot n=\left(\sum_{i=1}^{L} \frac{c_{i} q_{i} t_{s}}{2}+C_{s}\right) \cdot n,
$$

where $n=T / t_{s}, q_{i}=r_{i} t_{s}$.

Substituting the expressions for $n$ and $q_{i}$ in this relation:

$$
\mathrm{D}\left(\mathrm{t}_{\mathrm{s}}\right)=\left(\sum_{\mathrm{i}=1}^{\mathrm{L}} \frac{\mathrm{c}_{\mathrm{i}} \cdot \mathrm{r}_{\mathrm{i}} \cdot \mathrm{t}_{\mathrm{s}}^{2}}{2}+\mathrm{C}_{\mathrm{i}}\right) \cdot \frac{\mathrm{T}}{\mathrm{t}_{\mathrm{s}}}=\sum_{\mathrm{i}=1}^{\mathrm{L}} \frac{\mathrm{c}_{\mathrm{i}} \cdot \mathrm{r}_{\mathrm{i}} \cdot \mathrm{t}_{\mathrm{s}} \cdot \mathrm{T}}{2}+\mathrm{C}_{\mathrm{i}} \cdot \frac{\mathrm{T}}{\mathrm{t}_{\mathrm{s}}}
$$

The function $D\left(t_{s}\right)$ is a continuous function $t_{s}$, and its value tends to $+\infty$ as $t_{s} \rightarrow 0$.

Therefore, the minimum value of the cost function and, accordingly, the optimal value $t_{s}$ is reached when $d D\left(t_{s}\right) / d t_{s}=0$, i.e when

$$
\frac{\mathrm{dD}\left(\mathrm{t}_{\mathrm{s}}\right)}{\mathrm{dt}_{\mathrm{s}}}=\sum_{\mathrm{i}=1}^{\mathrm{L}} \frac{\mathrm{c}_{\mathrm{i}} \cdot \mathrm{r}_{\mathrm{i}} \cdot \mathrm{T}}{2}-\frac{\mathrm{C}_{\mathrm{s}} \cdot \mathrm{T}}{\mathrm{t}_{\mathrm{s}}^{2}}=0
$$

From these conditions, and determines the optimal time between adjacent replenishments of the warehouse $t_{s}^{*}$ :

$$
\mathrm{t}_{\mathrm{s}}^{*}=\sqrt{\frac{\mathrm{C}_{\mathrm{s}} \cdot 2}{\sum_{\mathrm{i}=1}^{\mathrm{n}} \mathrm{C}_{\mathrm{i}} \cdot \mathrm{r}_{\mathrm{i}}}}
$$

Then, in accordance with the expressions determining the quantities $q_{i}$, we get:

$$
\mathrm{q}_{\mathrm{i}}^{*}=\mathrm{r}_{\mathrm{i}} \cdot \mathrm{t}_{\mathrm{s}}^{*}=\mathrm{r}_{\mathrm{i}} \cdot \sqrt{\frac{\mathrm{C}_{\mathrm{s}} \cdot 2}{\sum_{\mathrm{i}=1}^{\mathrm{n}} \mathrm{C}_{\mathrm{i}} \cdot \mathrm{r}_{\mathrm{i}}}}
$$

\section{Conclusions}

Applying the economic-mathematical model for determining the optimal production capacity of the mine, an indicator equal to 4712000 tons was obtained. The production capacity of the Uchalinsky mine is 1560 thousand tons, and the Uzelginsky mine is 3,650 thousand tons. Having carried out the corresponding analysis of the production of JSC Uchalinsky GOK, the optimal production plan was obtained: the optimal copper production - 77961.4 rubles; the optimal production of zinc is 17975,66 rubles. The residual volume of production of the two main mines of JSC UGOK is 160 million tons of ore.

\section{References}

1. H.N. Gizatullin, Mathematical modeling of the development of mining and processing plants, 125 (Academy of Sciences of the USSR. The Ural Scientific Center, 1983)

2. L. Kagramanyan, Modeling and management of mining enterprises. 360 (M., Nedra, 1989)

3. A.U. Kazak, Financial policy in the corporate governance system: a textbook (Ekaterinburg: AMB Publishing, 2004) 
4. N.M. Kalinin, Models of management multicommodity stocks, 2 (Moscow, Institute for System Analysis, Russian Academy of Sciences)

5. M.S. Krass, Mathematical methods and models for undergraduates of economy: Textbook, 496 (St. Petersburg: Peter, 2010)

6. E.N. Lomkova, Economic-mathematical models of production management: a textbook, (Volgograd: RPK Polytechnic, 2005)

7. M.S. Fokina, A.V. Panyukov, Mining Information and Analytical Bulletin (Scientific and Technical Journal), 5 (2013)

8. G. Aggarwal, Computer Science Department, Stanford University, 94305:12, 3 (2013)

9. J. Chapuis, Revue Juridique polynesienne, 14:13, 6 (2007)

10. G. Gallego, Operations Research, 45:1, 5 (1997)

11. A. Halanay, Differential equations, discrete systems and control. Economic models, (Kluwer Academic Publishers, 2010)

12. M. P. Moffatt, Electronic Thesis and Dissertation Repository, 176, 155(2012) 